\title{
Impacto de la reprogramación celular (células de fibroblastos y cúmulos) en la producción de clones bovinos
}

\author{
Cortez, J.V. ${ }^{1,2}$; Segura, G.T.'; Murga, N.L. ${ }^{1}$ \\ ${ }^{1}$ Lab. Biotecnol. Anim., Reprod. y Mejoram. Genét., Instit. Investig. Ganad. y Biotecnol., \\ Univ. Nac. T.R. Mendoza, Amazonas, Perú. ${ }^{2}$ Lab. Genescol, Colombia. \\ E-mail: jenin.cortez@untrm.edu.pe
}

\begin{abstract}
Resumen
Cortez, J.V.; Segura, G.T; Murga, N.L.: Impacto de la reprogramación celular (células de fibroblastos y cúmulos) en la producción de clones bovinos. Rev. vet. 32: 2, 216-220, 2021. La clonación convencional consta de varios procesos que tienen un efecto directo en la producción embrionaria y la tasa de gestación, un factor primordial es la reprogramación de la célula utilizada como donante de núcleo. El objetivo del presente estudio fue evaluar el impacto de la reprogramación celular (células de fibroblastos y cúmulos) en la producción de clones bovinos. Las células donantes de núcleo se obtuvieron de fibroblastos y células de cúmulos para su reconstrucción con óvulos y cultivado durante $7 \mathrm{~d}$ hasta la fase de incubación/eclosión de blastocisto, para posteriormente ser transferidos a receptoras y evaluadas en los días 28,60 y 75 de gestación. Se evaluó número y porcentaje de citoplastos reconstruidos a la hora de fusión, obteniendo una mayor eficiencia con las células de cúmulos $(51,7 \pm 7,8)$ $(\mathbf{p}<0,05)$. El porcentaje de embriones obtenido al día 7 fue mayor con las células de fibroblastos $(36,1 \pm 8,4)$ en comparación con las células de cúmulos $(34,1 \pm 10,0)$. A los 28,60 y 75 días post-transferencia se evaluó permanencia de preñez, siendo significativamente superiores $(\mathbf{p}<0,05)$ los embriones generados con cúmulos de 16 células $(12,0 \%)$. La eficiencia de la reprogramación celular es similar en la procedencia de la célula, sin embargo existe un mayor porcentaje de retención de preñez con células de cúmulos como donante de núcleo.
\end{abstract}

Palabras clave: reproducción asistida, clivaje, reconstrucción, complejo célula/ovulo.

\begin{abstract}
Cortez, J.V.; Segura, G.T.; Murga, N.L.: Impact of cell reprogramming (fibroblast cells and clusters) on the production of bovine clones. Rev. vet. 32: 2, 216-220, 2021. Conventional cloning consists of several processes that have a direct effect on embryonic production and the pregnancy rate, a primary factor is the reprogramming of the cell used as a nucleus donor. The objective of the present study was to evaluate the impact of cell reprogramming (fibroblast cells and clusters) on the production of bovine clones. The nucleus donor cells were obtained from fibroblasts and cumulus cells for their reconstruction with ovules and cultured for $7 \mathrm{~d}$ until the blastocyst incubation / hatching phase, to be subsequently transferred to recipients and evaluated on day 28,60 and 75 of gestation. The number and percentage of reconstructed cytoplasts were evaluated at the time of fusion, obtaining greater efficiency with the cumulus cells $(51,7 \pm 7,8)(\mathbf{p}<0,05)$. The percentage of embryos obtained on day 7 was higher with fibroblast cells $(36,1 \pm 8,4)$ compared to cumulus cells $(34,1 \pm 10,0)$. At 28,60 and 75 days post transfer, pregnancy permanence was evaluated, being significantly higher $(p<0,05)$ the embryos generated with cumulus 16 cells $(12,0 \%)$. The efficiency of cell reprogramming is similar in the origin of the cell, however there is a higher percentage of pregnancy retention with cumulus cells as nucleus donor.
\end{abstract}

Key words: assisted reproduction, cleavage, reconstruction, cell / ovule complex.

\section{INTRODUCCIÓN}

Se han realizado diversos esfuerzos para superar el tratamiento de células somáticas con agentes químicos o biológicos y así facilitar la reprogramación o aumentar la capacidad de los ovocitos enucleados para inducir el proceso; para encontrar la etapa óptima de tiempo y ciclo celular para la enucleación, fusión y activación; así como para optimizar la activación y el período de cultivo in vitro ${ }^{19}$

Las mayores limitaciones biológicas de la clonación fueron que las células somáticas son completamente diferenciadas, con patrones de expresión génica que se correlacionan con la función del tejido del cual se originaron. 
Por esta razón, la mayoría de los investigadores concentraron sus trabajos en encontrar el tipo celular y las mejores condiciones de las células donantes para que la información genética pudiera ser reprogramada de forma eficiente en el citoplasto receptor, aumentando la eficiencia de la clonación somática.

Hasta la fecha se han utilizado muchos tipos celulares como donantes de núcleo para la producción de animales clonados. Dolly fue creada a partir de la reprogramación del núcleo de una célula de glándula mamaria ${ }^{18}$. Sin embargo, otros resultados exitosos incluyen la utilización de células de cúmulos ${ }^{17}$, fibroblastos fetales y adultos ${ }^{8,12}$, entre otras.

Por consiguiente, el presente trabajo tuvo como objetivo evaluar el impacto de la reprogramación celular (células de fibroblastos y cúmulos) en la producción de clones bovinos que permitan seleccionar el tipo de célula más eficiente como donante de núcleo en la clonación.

\section{MATERIAL Y MÉTODOS}

Localización del estudio y materiales utilizados. El estudio se realizó en el Laboratorio Genescol S.A. (Colombia), con apoyo logístico de los investigadores del Laboratorio de Biotecnología Animal, Reproducción y Mejoramiento Genético del Instituto de Investigación en Ganadería y Biotecnología, Universidad Nacional Toribio Rodriguez de Mendoza (Perú).

Colecta de los ovocitos. Los ovocitos fueron recuperados de folículos de 3 a $6 \mathrm{~mm}$ por el método de punción. El contenido folicular fue depositado en tubos con medio de manipulación TCM199-HEPES suplementado con $50 \mu \mathrm{g} / \mathrm{ml}$ de gentamicina y $10 \%$ (vol $/ \mathrm{vol}$ ) de suero fetal bovino (SFB).

Maduración in vitro de ovocitos. Los ovocitos se maduraron en grupos de 25 en placas de cuatro poci1los con medio TCM199 tamponado con bicarbonato suplementado con $0,6 \mathrm{mM}$ de glutamina, $0,2 \mathrm{mM}$ de piruvato, $0,01 \mathrm{UI} / \mathrm{ml}$ de FSH y $\mathrm{LH}, 1 \mathrm{mg} / \mathrm{ml}$ de estradiol, $50 \mu \mathrm{g} / \mathrm{ml}$ de gentamicina, $10 \mathrm{ng} / \mathrm{ml}$ de factor de

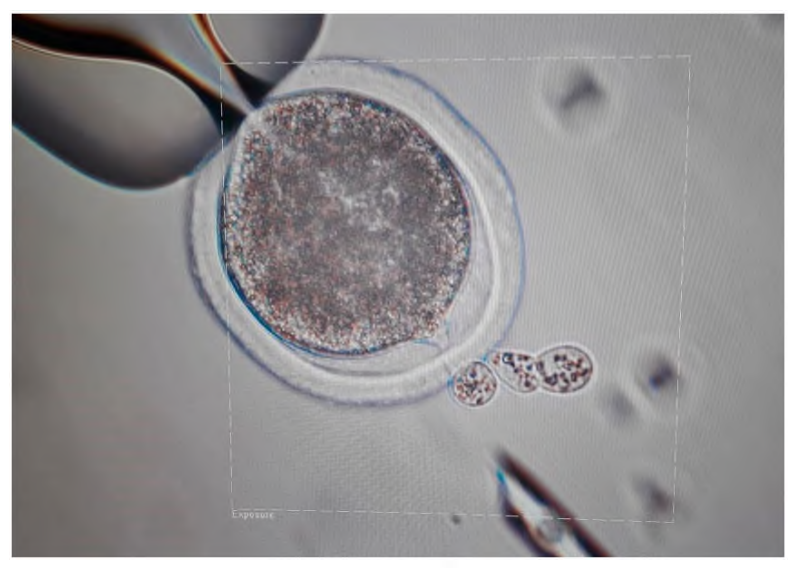

Figura 1. Proceso de enucleación. crecimiento epidérmico (EGF) y $10 \%$ de SFB a $38,5^{\circ} \mathrm{C}$ en $5 \% \mathrm{CO}_{2}$ con humedad máxima por 21 horas.

Preparación de citoplastos. Los óvulos maduros se incubaron en una solución de hialuronidasa de 0,3 $\mathrm{mg} / \mathrm{ml}$, seguidos de una agitación vorticial durante 6 minutos. Se confirmó la enucleación mediante tinción usando Hoechst 33342 y posterior visualización bajo luz UV. Para la manipulación se utilizó un par de micromanipuladores (Narishige, Japón) acoplados a un microscopio invertido (IX73, Olympus, Tokyo, Japón) y luz ultravioleta (filtro bloqueador UV-1 ${ }^{\mathrm{a}}$, con $365 \mathrm{~nm}$ de excitación y $400 \mathrm{~nm}$ de emisión) (Figuras 1 y 2).

Preparación de células somáticas. Las células somáticas fueron obtenidas de una vaca de la raza Gyr, siguiendo los protocolos establecidos por Tovar ${ }^{14}$. Las células de cúmulos fueron extraídas directamente de los ovocitos recuperados por aspiración folicular guiada por ecografía (Ovum Pick Up-OPU, Easote, Italia). Las células fueron separadas por pipeteo constante y luego fueron cultivadas por 5 días (pase 0). Después se crioconservaron utilizando un procedimiento estándar (sistema Mister Frosty). Las células descongeladas con mínimo 24 horas de confluencia $\left(\mathrm{G}_{1}\right)$ fueron utilizadas como donantes de núcleo para la reconstrucción embrionaria (Figura 3 - A y B).

Emparejamiento y electrofusión de célula donante con el citoplasto. Se emparejó una célula somática con un citoplasto. La fusión se realizó con un electrofusor BLS (Budapest, Hungría) y cámara de fusión (Modelo 450, 01-000209-01; BTX Corp, San Francisco, CA), en una solución de manitol a 0,3 M, 0,05 mM $\mathrm{CaCl}_{2}, 0,1 \mathrm{mM} \mathrm{MgCl}_{2}$ y alcohol polivinilo (PVA) a 1 $\mathrm{mg} / \mathrm{ml}$ inducida por un único pulso de corriente continua de $2 \mathrm{kV} / \mathrm{cm}$ por $9 \mu \mathrm{s}$. Los complejos fueron colocados en medio de retención con $20 \%$ de FBS durante 30 minutos para completar la fusión.

Activación y cultivo in vitro de embriones. LOS embriones reconstruidos sin signos de lisis fueron incubados por 2 horas en medio TCM-bicarbonato con

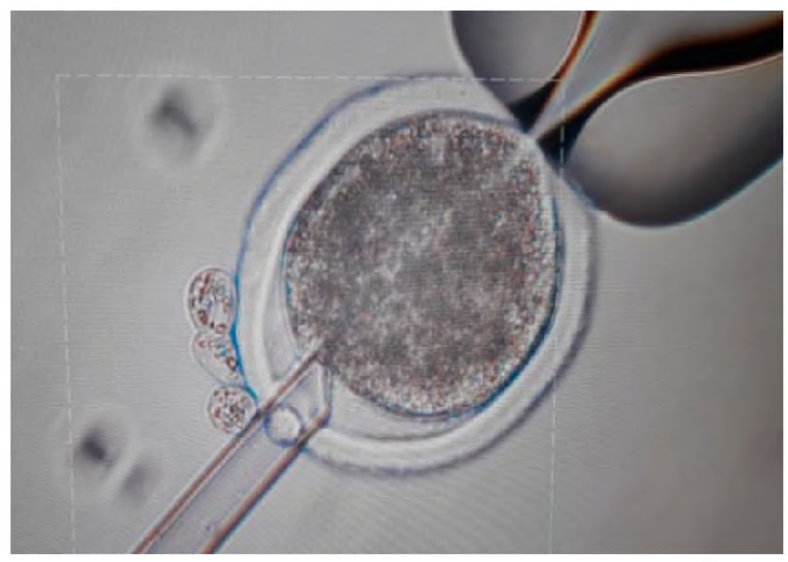

Figura 2. Proceso de transferencia nuclear somática. 
$10 \%$ de SFB en $5 \%$ de $\mathrm{CO}_{2}$ a $38,5^{\circ} \mathrm{C}$ para iniciar su reprogramación. Posteriormente estos fueron activados mediante incubación durante 5 minutos a temperatura ambiente en $7 \%$ de etanol en medio de mantenimiento suplementado con $20 \%$ de SFB, seguido de una incubación de 5 horas en el mismo medio suplementado con 5 $\mu \mathrm{g} / \mathrm{ml}$ de citocalasina B y $10 \mu \mathrm{g} / \mathrm{ml}$ de cicloheximida a $38,5^{\circ} \mathrm{C}$ en atmósfera de $\mathrm{CO}_{2}$ al $5 \%$. Posteriormente, los embriones se cultivaron en placas de cuatro pocillos en medio SOFaaci ${ }^{7}$ suplementado con albúmina bovina (BSA) al 0,3\%. La placa de cultivo se selló en una bolsa hermética y se gasificó con una mezcla de aire que contenía $5 \% \mathrm{CO}_{2}, 5 \% \mathrm{O}_{2}$ y $90 \%$ de $\mathrm{N}_{2}$, para posteriormente ser incubado por 7 días a $38,5^{\circ} \mathrm{C}$.

Transferencia de embriones y control de la preñez. Las transferencias se realizaron en el departamento de Santander (Colombia), en vacas receptoras sincronizadas con cuerpo lúteo de más de $16 \mathrm{~mm}$ de diámetro en uno de los ovarios. Se transfirieron los embriones al cuerno uterino ipsolateral del CL funcional con el uso de una pistola de transferencia de embriones (21") con fundas punta de acero. La tasa de gestación se evaluó a los días 28,60 y 75 mediante ultrasonografía.

Análisis estadístico. Los dos tipos de células somáticas fueron comparadas en función a la proporción de dobletes fusionados, producción de embriones clonados y permanencia de preñez. Para ello se aplicó una prueba «t $»$ de Student para muestras o grupos de observaciones independientes, con un nivel de significancia de 0,05 . Previamente se realizó una prueba de homogeneidad de varianza, además de haberse determinado el comportamiento normal de las observaciones.

\section{RESULTADOS}

Un total de 3244 ovocitos de grados I y II fueron seleccionados para maduración, presentando cuerpo polar $89 \%$, de los cuales se formaron 2887 complejos célula/cúmulos.

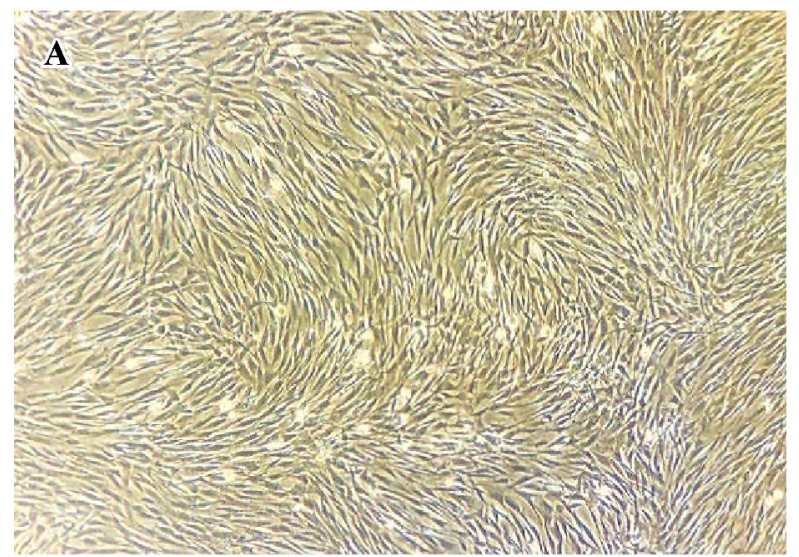

Figura 3. Fibroblastos de piel y células de cúmulos en cultivo in vitro. A) células de piel en confluencia. B) células de cúmulos en crecimiento.

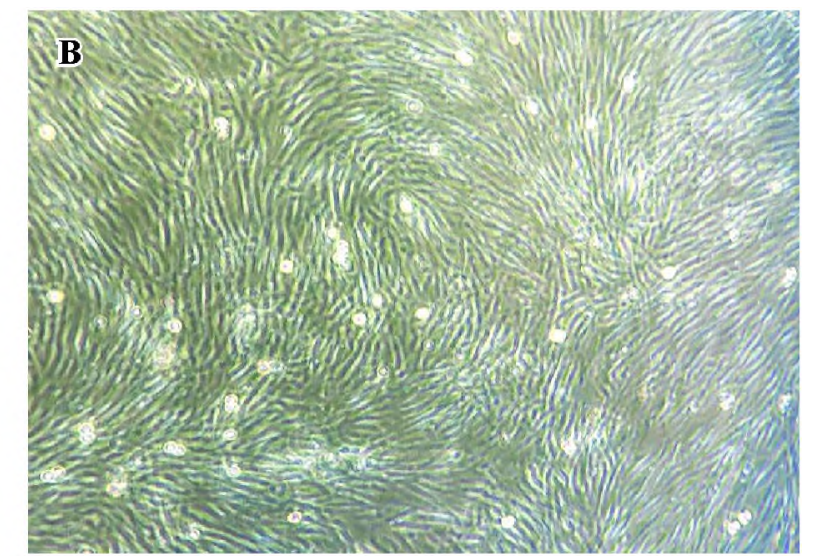

Se utilizaron dos líneas celulares (fibroblastos de piel adulta y células de cúmulos) para ser empleados como carioplastos (núcleo) y evaluar su impacto de reprogramación en la producción de embriones clones.

Se obtuvo una mayor eficiencia de reconstrucción con células de cúmulos $\left(\mathrm{N}^{\circ}=168\right)$ a comparación con las células de fibroblasto, siendo la variación entre los dos tipos de células estadísticamente significativa $(p<0,05$; Tabla 1$)$.

En total, se reconstruyeron 1285 citoplastos por transferencia nuclear de las dos células somáticas, sin embargo, solo entraron a cultivo el $76 \%(n=976)$. Se obtuvo una diferencia del $2 \%$ en los porcentajes de tasa de clivaje evaluado a los 2 días de cultivo in vitro, sin embargo, esta no fue significativa $(p<0,05)$. Los porcentajes de blastocistos se registraron el día 7 de cultivo in vitro presentando una mínima diferencia porcentual, la cual no fue estadísticamente significativa $(\mathrm{p}<0,05$; Tabla 2).

Se transfirieron 246 blastocistos viables de 7 días a 246 receptoras sincronizadas en el día 7 después de la ovulación, 113 embriones producidos a partir de fibroblastos de piel y 133 embriones producidos a partir de células de cúmulos (Tabla 3). Se evaluó permanencia de gestación a los 28 y 60 días sin encontrar diferencias significativas $(p<0,05)$ entre los tipos de células utilizados para la reprogramación celular. Nuevamente se evaluó permanecía en el término de la etapa crítica del primer tercio de gestación (75 días), presentando diferencias significativas $(p<0,05)$ en número y porcentaje con células reprogramadas de la granulosa (Tabla 3 ).

\section{DISCUSIÓN}

La transferencia nuclear de células somáticas, originalmente propuesta a principios de 1900 como una forma de probar la retención de la potencia genómica durante la especialización celular, ahora se lleva a cabo en una gran cantidad de especies, utilizando diversas combinaciones de células núcleo donante-receptor y una amplia gama de metodologías ${ }^{1}$. 
Tabla 1. Citoplastos reconstruidos con fibroblastos de piel y células del cúmulos.

\begin{tabular}{lccc}
\hline cétulas & $\begin{array}{c}\text { complejo } \\
\text { célula / óvulo }\left(\mathrm{N}^{\circ}\right)\end{array}$ & $\begin{array}{c}\text { reconstruidos } \\
\left(\mathrm{N}^{\circ}\right)\end{array}$ & $\begin{array}{c}\text { reconstruidos } \\
(\%)\end{array}$ \\
\hline fibroblastos de piel & 1487 & 556 & $37,4 \pm 6,8^{\mathrm{b}}$ \\
células del cúmulos & 1400 & 724 & $51,7 \pm 7,8^{\mathrm{a}}$ \\
\hline
\end{tabular}

a,b superíndices diferentes dentro de columnas indican diferencia estadística $(\mathrm{p}<0,05)$.

Tabla 2. Desarrollo embrionario con fibroblastos de piel y células del cúmulos.

\begin{tabular}{lccc}
\hline células & $\begin{array}{c}\text { reconstruidos cultivados } \\
\left(\mathrm{N}^{\circ}\right)\end{array}$ & $\begin{array}{c}\text { clivaje } \\
(\%)\end{array}$ & $\begin{array}{c}\text { blastocistos } \\
(\%)\end{array}$ \\
\hline fibroblastos de piel & 427 & $71,1 \pm 5,1$ & $34,1 \pm 10,0$ \\
células del cúmulos & 549 & $73,1 \pm 5,4$ & $36,1 \pm 8,4$ \\
\hline
\end{tabular}

${ }^{a, b}$ superíndices diferentes dentro de columnas indican diferencia estadística $(\mathrm{p}<0,05)$.

Tabla 3. Gestaciones generadas con fibroblastos de piel y células del cúmulos.

\begin{tabular}{lccccc}
\hline células & $\begin{array}{c}\text { embriones } \\
\text { transferidos } \\
(\mathrm{n})\end{array}$ & $\begin{array}{c}\text { receptoras } \\
(\mathrm{n})\end{array}$ & $\begin{array}{c}\text { dia 28 } \\
(\mathrm{n})(\%)\end{array}$ & $\begin{array}{c}\text { permanencia } \\
\text { día 60 } \\
(\mathrm{n})(\%)\end{array}$ & $\begin{array}{c}\text { día 75 } \\
(\mathrm{n})(\%)\end{array}$ \\
\hline fibroblastos de piel & 113 & 113 & $52(46,0)$ & $28(24,8)$ & $8(7,1)^{\mathrm{a}}$ \\
células de cúmulos & 133 & 133 & $63(47,4)$ & $33(25,6)$ & $16(12,0)^{\mathrm{b}}$ \\
\hline
\end{tabular}

${ }^{\mathrm{a}, \mathrm{b}}$ superíndices diferentes dentro de columnas indican diferencia estadistica $(\mathrm{p}<0,05)$

La capacidad de reconstrucción de la célula con el citoplasto y la reprogramación celular son factores primordiales para tener éxito en un proceso de producción de embriones clones, estos factores se ven influenciados por el tipo de célula utilizada como donante de núcleo (carioplastos) ${ }^{11}$.

El estudio presentó mayor eficiencia de reconstrucción con células de cúmulos $\left(51,7 \pm 7,8^{\mathrm{a}}\right)$ a comparación con las células de fibroblasto $\left(37,4 \pm 6,8^{\mathrm{b}}\right)$, presentando diferencia estadísticamente significativa $(p<0,05)$. Ello difiere del estudio realizado en el año 2017 con parte del mismo equipo de investigadores, donde no se encontraron diferencias estadísticas entre reconstruidos con células de fibroblastos y células de cúmulos (cumulus), lo cual podría estar influenciado por la técnica de clonación utilizada ${ }^{2}$.

El porcentaje de reconstrucción de las dos líneas celulares utilizadas en la reprogramación para la formación de embriones clones se encuentra en el promedio $(37,4 \% ; 51,7 \%)$ de resultados reportados por otros autores con referencia a la técnica de clonación con micromanipuladores y HMC, independientemente de las células donantes ${ }^{6,16}$.

La producción de blastocistos al día 7 de cultivo no se vio influenciada por la diferencia estadística en los porcentajes de reconstrucción, siendo los porcentajes de producción similares con la reprogramación de células de fibroblastos $(34,1 \%)$ y células de cúmulos $(36,1 \%)$, presentando una ligera superioridad con el empleo de células de cúmulos.

Tales resultados son similares a los reportados en un trabajo anterior ${ }^{9}$, donde se evaluó la producción de embriones clones (blastocistos) generados a partir de células donantes de núcleos provenientes de diversos tejidos (adultos, fetales, pantorrilla, gametos femeninos y masculinos), no encontrándose diferencias en los porcentajes de producción.

Los promedios de producción de blastocistos de la investigación se encuentran dentro del promedio mundial $(30 \%)$ de producción de blastocistos bovinos mediante transferencia nuclear somática con micromanipuladores ${ }^{4}$.
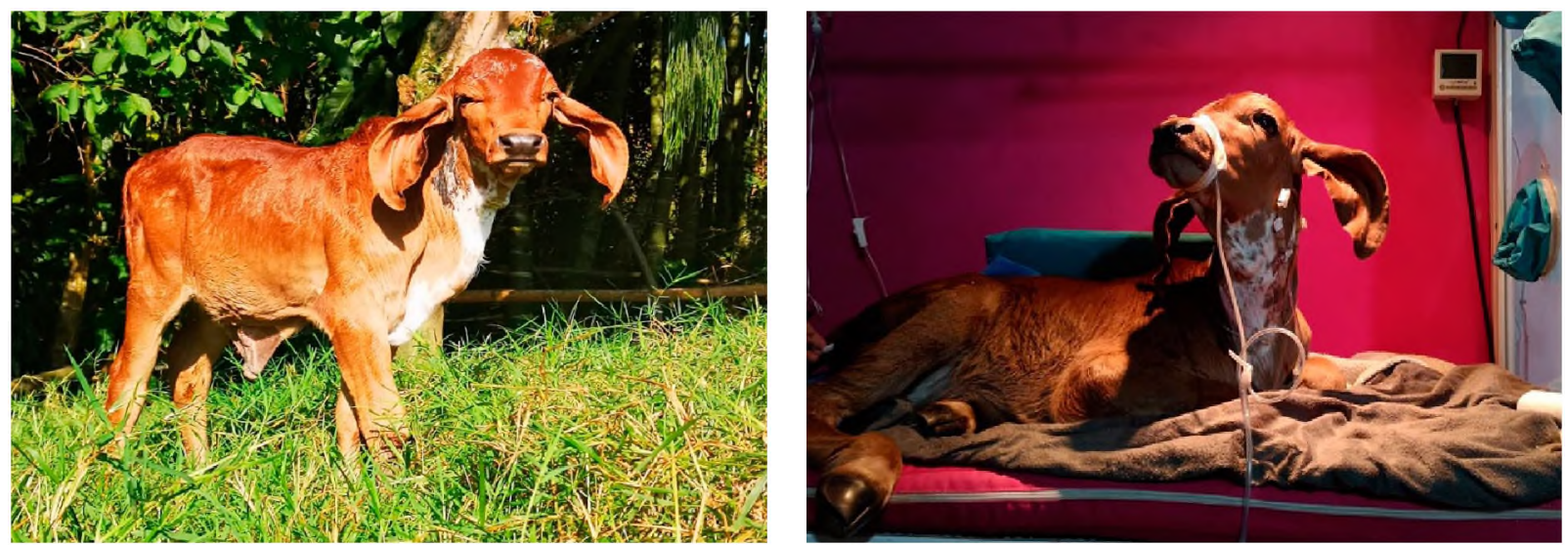

Figura 4. Terneros clonados mediante la técnica de transferencia nuclear de células somáticas (SCNT). A: ternera Gyr Ofelia-C1, en el día del nacimiento. B) ternera Gyr Ofelia-C2. 
Los resultados de esta investigación -en permanencia gestacional evaluada a los 28 y 60 días- se encuentran dentro de los promedios $>50 \%$ de trabajos previos realizados ${ }^{2,3}$, lo cual concuerda con otros autores ${ }^{10}$, quienes obtuvieron un porcentaje de permanencia con células del cúmulus de $28 \%$ y piel de $50 \%$ en los primeros meses de gestación, y con porcentajes de nacimientos de $19 \%$ con células de cúmulus y $20 \%$ células de piel, conjuntamente se conoce que los embriones clonados presentan una tasa elevada $\geq 60 \%$ de mortalidad embrionaria en el periodo de gestación temprana ${ }^{5,13}$.

Ello concuerda con los resultados obtenidos a los 75 días de gestación donde la permanencia disminuyó en un porcentaje de $7,1 \%$ para embriones producidos a partir de la reprogramación de células de fibroblastos y $12,0 \%$ a partir de la reprogramación de células de cúmulos.

En conclusión, los estudios demostraron que las líneas celulares de piel y cúmulos son células que pueden ser utilizadas como donantes de núcleos para la clonación de terneros (Figura 4).

Sin embargo, es importante continuar con las investigaciones en biología celular para saber la procedencia exacta de las células donantes de núcleo, ya que podríamos estar utilizando fibroblastos todo el momento.

\section{REFERENCIAS}

1. Amarnath DL et al. 2014. Nuclear origins and clone phenotype. 10.1016/B978-0-12-386541-0.00003-5.

2. Cortez $\mathbf{J}$ et al. 2017. Capacidad de dos líneas celulares para la producción de embriones clonados mediante transferencia nuclear de células somáticas. Rev Investig Vet Perú 28: 4, 928-938.

3. Cortez $\mathbf{J}$ et al. 2018. High pregnancy and calving rates with a limited number of transferred handmade cloned hovine embryos. Cellular Reprogr 20: 1, 4-8.

4. First N, Beyhan Z, Ambroggio J. 2002. Cloning of cattle, National Human Genome Research Institute, www.genome.gov >about-genomics fact-sheets, 375-390.

5. Galli C, Duchi R, Moor RM, Lazzari G. 1999. Mammalian leukocytes contain all the genetic information necessary for the development of a new individual. Cloning 3 : 161-170.

6. Hayes $\mathbf{O}$ et al. 2005. La confluencia celular es tan eficaz como la inanición de suero para inducir la detención en la fase G0/G1 del ciclo celular en células granulosas y fibroblásticas de ganado. Ciencia de la Reproducción Animal 87: 181-192.
7. Holm P et al. 1999. High bovine blastocyst development in a static in vitro production system using SOFaa medium supplemented with sodium citrate and myo-inositol with or without serum-proteins. Theriogenology 52: 4, 683-700

8. Kato Y et al. 1998. Eight calves cloned from somatic cells of a single adult. Science (New York) 282: 2095-2098.

9. Kato Y, Tani T, Tsunoda Y. 2000. Cloning of calves from various somatic cell types of male and female adult, newborn and fetal cows. Journal Reprod \& Fertility 120: 2 , 231-237.

10. Kato Y, Tsunoda Y. 2014. Donor cell type and cloning efficiency in mammals. Principles of Cloning 19: 127-134.

11. Miyoshi K, Rzucidlo SJ, Pratt SL, Stice SL. 2003. Improvements in cloning efficiencies may be possible by increasing uniformity in recipient oocytes and donor cells. Biol Reprod 68: 1079-1086.

12. Rodriguez ZS, Schellander K, Lewin HA. 2008. Biological interpretations of transcriptomic profiles in mammalian oocytes and embryos. Reproduction (Cambridge, England), 135: 2, 129-139.

13. Tamada H, Kikyo N. 2004. Nuclear reprogramming in mammalian somatic cell nuclear cloning. Cytogenetic \& Genome Research 105: 2-4, 285-291.

14. Tovar $\mathbf{H}$ et al. 2008. Cold storage of biopsies from wild endangered native Chilean species in field conditions and subsequent isolation of primary culture cell lines. In vitro cellular \& developmental biology. Animal 44: 8-9, 309320.

15. Vajta G, Holm P, Greve T, Callesen H. 1997. The submarine incubation system, a new tool for in vitro embryo culture: techn.report. Theriogenology 48: 1379-1385.

16. Vajta $\mathbf{G}$ et al. 2003. Handmade somatic cell cloning in cattle: analysis of factors contributing to high efficiency in vitro. Biology of Reproduction 68: 2, 571-578.

17. Wakayama T et al. 1998. Full-term development of mice from enucleated oocytes injected with cumulus cell nuclei. Nature 394: 6691, 369-374.

18. Wilmut I et al. 1997. Viable offspring derived from fetal and adult mammalian cells. Nature 385: 6619, 810-813.

19. Wilmut I, Bai Y, Taylor J. 2015. Somatic cell nuclear transfer: origins, the present position and future opportunities. Philosophical transactions of the Royal Society of London. Series B, Biological sciences 370: 1680, 20140366 